\title{
Entre o social e o político : A luta pela definição do modelo de acesso à justiça em São Paulo
}

Between the Social and the Political: The Struggle to Define the Model for Access

to Justice in São Paulo

Entre le social et le politique : la lutte pour la définition du modèle d'accès à la justice à São Paulo

\section{Élida Lauris}

\section{OpenEdition}

\section{Journals}

Edição electrónica

URL: http://journals.openedition.org/rccs/1464

DOI: $10.4000 /$ rccs. 1464

ISSN: 2182-7435

\section{Editora}

Centro de Estudos Sociais da Universidade de Coimbra

\section{Edição impressa}

Data de publição: 1 Dezembro 2009

Paginação: 121-142

ISSN: 0254-1106

\section{Refêrencia eletrónica}

Élida Lauris, «Entre o social e o político : A luta pela definição do modelo de acesso à justiça em São Paulo », Revista Crítica de Ciências Sociais [Online], 87 | 2009, colocado online no dia 15 outubro 2012, criado a 19 abril 2019. URL : http://journals.openedition.org/rccs/1464; DOI : 10.4000/rccs.1464 


\section{ÉLIDA LAURIS}

\section{Entre o social e o político: \\ A luta pela definição do modelo de acesso à justiça em São Paulo'}

O artigo explora as combinações possíveis na configuração política do acesso à justiça nas sociedades contemporâneas. Tendo como ponto de partida as mutações do significado sociopolítico do acesso no Estado moderno, recorre ao caso concreto da consolidação do sistema de assistência jurídica em São Paulo para explorar as lutas sociais e os confrontos políticos que subjazem à decisão da política pública de acesso à justiça na actualidade.

Palavras-chave: acesso à justiça; acesso ao direito; apoio judiciário; direitos colectivos; justiça; reforma jurídica; São Paulo (Brasil); sociologia do direito.

\section{Introdução}

A garantia formal do acesso à justiça e a previsão da igualdade de todos perante a lei têm funcionado como indicadores expressivos do carácter democrático das sociedades contemporâneas. Não é à toa que a igualdade e a garantia do acesso estão consagradas como princípios orientadores e direitos fundamentais da ordem política na constituição de diferentes países. Todavia, a par desta consagração simbólica, um número significativo de pessoas vive e interage à margem do sistema jurídico e económico oficial. Nas situações de conflitos e de demandas por direitos, por sua vez, um vasto conjunto de necessidades jurídicas e de problemas da população colide com a total ausência de cobertura por parte do sistema legal ou, pelo menos, com uma cobertura ineficiente.

\footnotetext{
${ }^{1}$ Este artigo apresenta os resultados preliminares do trabalho de campo realizado no âmbito da tese de doutoramento "Judiciário e democracia: um estudo comparado do acesso à justiça em São Paulo e Portugal", sob orientação do Professor Doutor Boaventura de Sousa Santos. Uma nota de agradecimento é devida a Cristiana Gaspar e Fátima Antunes, pelo apoio na transcrição das entrevistas, e a Marina Henriques, pelo auxílio na revisão do texto. Pelo apoio irrestrito e estímulo intelectual constante, agradeço especialmente a Boaventura de Sousa Santos, Conceição Gomes e Madalena Duarte.
} 
Estas discrepâncias nas regras de distribuição dos recursos e na abrangência da cobertura do sistema oficial, na prática, traduzem-se em distintos patamares de inclusão social e de cidadania. ${ }^{2}$ A relação entre desigualdade, exclusão, justiça e direitos assume os contornos de um círculo vicioso: em virtude dos níveis de desigualdade e dos mecanismos de exclusão, o acesso à justiça e aos direitos é negado; sendo este negado, mantêm-se os padrões de desigualdade e exclusão existentes. Consequentemente, o tema do acesso tem-se destacado sobretudo pela sua negação, isto é, pela perpetuação de processos de diferenciação e hierarquização social enquanto causas e consequências das limitações ao acesso à justiça e aos direitos.

Se são evidentes os limites da capacidade do Estado na realização material irrestrita do acesso à justiça, não é menos verdade que as oportunidades de acesso podem contribuir significativamente para a produção de resultados socialmente mais justos. Num quadro normativo em que, a par da baixa efectividade de um conjunto de direitos - sobretudo direitos de bem-estar social - estão previstos procedimentos que os garantem, o acesso à justiça e em especial aos tribunais assume um importante papel de justiça distributiva. Neste caso, as expectativas face à função social da justiça podem ser tanto mais elevadas quanto maior for a vulnerabilidade dos cidadãos e a crise dos esquemas de protecção social vigentes.

A decisão sobre a partilha de direitos, em regra, contrapõe interesses sociais divergentes (empregadores versus trabalhadores, consumidores versus produtores, homens versus mulheres, cidadão versus Estado, etc.). Logo, a reivindicação de uma solução jurídica sobre a titularidade do direito, muito embora aparente ser uma solução meramente técnica, pode assumir um forte conteúdo de mudança do status quo social e político (Santos, 1987). Devido às suas potencialidades no âmbito da transformação e justiça social, o conceito de acesso à justiça deve desenvolver-se num quadro conceptual amplo de articulação entre agência e estrutura na distribuição dos direitos, o que inclui a mobilização de procedimentos e mecanismos judiciais (representação em juízo, consulta jurídica, defesa adequada, devido processo legal), instituições estatais não judiciais (administração pública) e instituições não estatais (partidos políticos, organizações não-governamentais) através da iniciativa de cidadãos, empresas e

\footnotetext{
${ }^{2}$ No que se refere aos graus de exclusão e acesso aos direitos, Santos (2003: 25) argumenta a existência de três tipos de sociedade civil: a sociedade civil íntima (indivíduos caracterizados pela hiper-inclusão, gozam de um nível elevado de inclusão social e desfrutam do leque completo de direitos), a sociedade civil estranha (a inclusão social tem uma qualidade baixa ou moderada, a exclusão é atenuada por algumas redes de protecção e acesso escasso aos direitos sociais, económicos e culturais) e a sociedade civil incivil (totalmente excluídos, na prática, não possuem quaisquer direitos).
} 
grupos sociais, circunscrevendo não só conflitos individuais, mas também questões colectivas e de direitos difusos, com especial atenção aos conflitos estruturais e às clivagens socioeconómicas existentes (género, classe, etnicidade, etc.). Dado o papel dos tribunais enquanto órgão de soberania dedicado à aplicação e à garantia dos direitos, em última instância, o acesso à justiça strictu sensu, isto é, o acesso à administração da justiça pode assumir uma importância assinalável.

O impacto da crise das políticas de bem-estar na capacidade das instituições oficiais em manter grandes sistemas públicos de assistência jurídica abalou a confiança teórica nos modelos universais de acesso, pondo em causa a eficácia da sua resposta enquanto política pública. O debate sobre acesso à justiça passou então a orientar-se sob o signo do afunilamento e da selectividade através de limitações de financiamento, de restrições na definição dos beneficiários e dos problemas jurídicos, de redução do alcance dos serviços, entre outros. Assim, o acesso à justiça tem-se afastado gradualmente do âmbito da protecção social do Estado, fragmentando-se na administração de um mercado de serviços jurídicos e de mecanismos alternativos de resolução de conflitos (Flood, 2009). Neste novo contexto, as mudanças na orientação da agenda política global e local do acesso, as diferentes aspirações das profissões jurídicas, os avanços e recuos na relação entre cidadania e justiça fazem do modelo actual de acesso ao direito e à justiça em cada sociedade uma arquitectura política instável.

Partindo das transformações do quadro político e teórico que subjazem à actual discussão sobre o acesso, este artigo analisa as diferentes dinâmicas na configuração do modelo de acesso à justiça em São Paulo. A pró-actividade de movimentos e organizações sociais e o envolvimento das instituições e das diferentes profissões jurídicas no debate sobre as prioridades do investimento público no acesso ao direito e à justiça fazem de São Paulo um estudo de caso singular para se reflectir sobre o papel dos diferentes actores sociais e das instituições na luta pela democratização do direito através da ampliação do acesso. Os dados apresentados foram recolhidos através de entrevistas semi-estruturadas, aplicadas a líderes de organizações e movimentos sociais, dirigentes políticos, defensores públicos, representantes de associações profissionais, juízes e magistrados do Ministério Público. O trabalho de campo decorreu no período de Agosto a Novembro de 2008 e ao todo foram realizadas 38 entrevistas, para além do acompanhamento de reuniões dos movimentos sociais e do Movimento de Valorização da Defensoria Pública. 


\section{A evolução do estado da arte do acesso à justiça}

Numa perspectiva sociopolítica, a adopção de modelos de acesso à justiça pelos estados tem resultado da combinação e do confronto entre as estratégias de actores e instituições locais face ao imperativo de reformas globais voltadas para a redefinição do papel do sistema de justiça e da efectividade de direitos no âmbito da cooperação entre direito e desenvolvimento.

Neste sentido, Santos (2007) identifica dois grandes campos de luta no que se refere à definição do papel da justiça e das reformas jurídicas na actualidade. De um lado, um campo hegemónico, cujos protagonistas são o Banco Mundial, o Fundo Monetário Internacional e as grandes agências multilaterais e internacionais de ajuda ao desenvolvimento. Este campo concentra grande parte das reformas do sistema judiciário por todo o mundo - vinculando-se aos negócios, aos interesses económicos - e reclama por uma justiça eficiente, célere, que permita, efectivamente, a previsibilidade dos negócios, dê segurança jurídica e garanta a salvaguarda dos direitos de propriedade.

De outro lado, um campo contra-hegemónico em que actuam os cidadãos que tomaram consciência dos direitos significativos trazidos sobretudo pelos processos de mudança constitucional - nomeadamente direitos sociais e económicos - e vêem na utilização do direito e dos tribunais uma ferramenta de mudança social. O campo contra-hegemónico indaga qual o papel dos tribunais ante as aspirações dos cidadãos marginalizados a serem inclú́dos no contrato social.

A este propósito, a intensidade com que a globalização jurídica se repercute na ordem política (Santos, 2002) e a posição assumida pelos actores e instituições locais no que toca à definição da política pública de acesso à justiça são factores determinantes na significação dos modelos de acesso em cada sociedade. Num nível local, as tensões e contradições vivenciadas pelos agentes políticos, pelas profissões jurídicas e pelos cidadãos podem influenciar de maneira expressiva a configuração do sistema de acesso.

Do ponto de vista das instituições políticas, a preocupação com o reforço das garantias de igualdade dos cidadãos no recurso ao direito e à justiça tem colidido com os pressupostos de uma nova gestão pública centrada na racionalização dos serviços. Deste modo, o desejo de ampliação, propagação e proximidade das estruturas encontra limites nos propósitos de concentração dos serviços jurídicos e na redução de custos. No que se refere às aspirações das profissões do direito, verificam-se duas tendências distintas. Por um lado, o estatuto de excepcionalidade e os privilégios das carreiras jurídicas traduzem-se numa lógica top down de manutenção da dominação e do exercício do poder e, consequentemente, repercutem-se na distância social e 
simbólica da justiça. ${ }^{3}$ Por outro lado, é possível assistir a práticas de dissidência de alguns operadores, materializadas especialmente na adopção de posições críticas em relação aos poderes constituídos e no recurso à utilização contra-hegemónica das ferramentas jurídicas como, por exemplo, a advocacia estratégica dos interesses e das necessidades dos cidadãos (Comaille, 2009).

As antinomias constantes da agenda política e da prática jurídica dos profissionais do direito podem concretizar-se através de três manifestações distintas dos cidadãos em relação ao direito e à justiça: o evitamento, o afastamento e a apropriação (ibidem). Na lógica de evitamento, confrontados com a ineficácia da lei e as fraquezas da justiça (lentidão, custos exorbitantes, arrogância das profissões jurídicas e abandono crescente de indivíduos), os cidadãos afastam-se, esquivando-se do recurso às estruturas jurídicas e judiciais. A lógica de afastamento manifesta-se na auto-regulação dos grupos sociais e das organizações e na crescente capacitação dos indivíduos de forma a manter uma independência face ao sistema legal e às políticas públicas na área do acesso. Por fim, na lógica de apropriação, o direito e a justiça são ressignificados enquanto ferramentas de luta dos grupos e movimentos sociais (Mccan, 1994).

Diferentes configurações políticas do acesso à justiça podem resultar da combinação entre as aspirações dos actores para a arquitectura dos serviços jurídicos e para o papel a ser desempenhado pela justiça. A configuração política do acesso à justiça pode oscilar, em tipos ideais, entre um modelo mais democrático e um modelo mais tecnocrático (Comaille, 2009).

Numa configuração democrática, o modelo pende para uma opção política de promoção da igualdade através da garantia do acesso, numa estratégia de maior apropriação individual ou colectiva dos serviços e ferramentas jurídicas articulada com a pró-actividade das profissões jurídicas na utilização estratégica do direito para o atendimento das necessidades dos cidadãos. Numa configuração mais tecnocrática, a promoção do acesso é permanentemente filtrada pela optimização do funcionamento das instituições jurídicas, podendo redundar na maior convergência e selectividade da prestação pública de acesso à justiça e na fragmentação dos serviços jurídicos numa rede público-privada. ${ }^{4}$

\footnotetext{
3 Se, por um lado, o ritual judicial (Garapon, 1997) é valorizado pela segurança jurídica e imparcialidade dos procedimentos, por outro lado opera igualmente assimetrias, demarcando a diferenciação e superioridade dos profissionais do direito. Neste sentido, cf. Sinhoretto (2006).

${ }^{4}$ Uma configuração tecnocrática, inspirada pelos princípios do liberalismo económico, pode ainda sustentar-se numa segmentação do mercado de acesso ao direito e à justiça, apostando numa justiça profissional e institucionalizada para certas categorias sociais favorecidas e operadores económicos, e numa justiça "profana" informal e desprofissionalizada para grupos sociais mais desfavorecidos (Comaille, 2009).
} 


\section{O movimento global de acesso à justiça}

A teorização do movimento de acesso à justiça em diferentes países correspondeu, num primeiro momento, a uma ambição democrática de defesa do investimento na criação de sistemas nacionais abrangentes de acesso aos direitos e confrontou-se, posteriormente, com os limites tecnocráticos da racionalização dos serviços e controlo dos gastos públicos.

Uma das conceptualizações de maior envergadura no âmbito do acesso ao direito e à justiça resulta do estudo comparado e multidisciplinar coordenado por Mauro Cappelletti no âmbito do Projecto Florença. ${ }^{5}$ De acordo com Cappelletti e Garth (1988), a evolução do conceito teórico de acesso acompanha as mutações do Estado e, nesse sentido, progride de uma perspectiva formal, vazia de efectividade, típica do Estado liberal, para adquirir um significado material com a consagração de direitos económicos e sociais pelo Estado-Providência. Tal mudança de significado decorre da evidência de ser despropositada a consagração de direitos que exijam uma prestação positiva do Estado sem a previsão de mecanismos para sua reivindicação (Cappelletti e Garth, 1988: 11).

Se é certo que um Estado democrático, para além da proclamação de direitos, deve garanti-los, a efectividade do acesso à justiça é um requisito fundamental para a sua concretização. O reconhecimento dos obstáculos a serem transpostos para um direito de acesso à justiça efectivo é, portanto, a condição primeira de uma ordem jurídica igualitária. A par dos resultados do Projecto Florença, a reflexão académica do período veio demonstrar que as vantagens de utilização do sistema jurídico são aproveitadas sobretudo pelos litigantes organizacionais, ${ }^{6}$ enquanto os obstáculos são mais pronunciados para as pequenas causas, ${ }^{7}$ para os litigantes individuais, especialmente

\footnotetext{
${ }^{5}$ O projecto reuniu mais de uma centena de investigadores de diferentes áreas (direito, sociologia, ciência política, antropologia, psicologia) dedicando-se ao estudo do sistema de acesso em cerca de trinta países. Os resultados da investigação foram publicados em 1978/1979 em quatro volumes: Volume I (Access to justice: A world survey, coordenado por Cappelletti e Garth); Volume II (Access to Justice: Studies of promising institutions, coordenado por Cappelletti e Weisner), Volume III (Access to Justice: Emerging perspectives and issues), Volume IV (Patterns in Conflict Management: Essays in the etnography of law. Access to justice in an anthropological perspective, coordenado por Koch). Posteriormente foi publicado, em 1981, o volume Access to Justice and Welfare State.

${ }^{6}$ Cappelleti e Garth (1988) argumentam a existência de uma variação significativa no acesso à justiça de acordo com as possibilidades das partes, nomeadamente, no que respeita a diferenças de condições financeiras, na aptidão para reconhecer um direito e propor uma acção e no facto de serem litigantes eventuais ou habituais do sistema. De acordo com Galanter (1974) os litigantes habituais (repeat players), como acumulam muitos casos, trazem consigo um conjunto de vantagens no recurso às instituições jurídicas: maior experiência, economia de escala, distribuição dos riscos, entre outros. 7 "As causas que envolvem somas relativamente pequenas são mais prejudicadas pela barreira dos custos. Se o litígio tiver de ser decidido por processos judiciários formais, os custos podem exceder o montante da controvérsia ou, se isso não acontecer, podem consumir o conteúdo do pedido a ponto de tornar a demanda uma futilidade" (Cappelletti e Garth, 1988: 19).
} 
os mais pobres, ${ }^{8}$ e para a construção de soluções processuais e institucionais que possibilitem a reivindicação dos interesses difusos e colectivos.

Ao discutir as soluções práticas que os sistemas de acesso à justiça de diferentes países vieram a adoptar, Cappelletti e Garth argumentam a existência de um conjunto articulado de reformas jurídicas com o objectivo de atacar, de forma compreensiva, as barreiras ao acesso. Estas iniciativas de reforma foram categorizadas, em sequência mais ou menos cronológica, no que ficou conhecido como ondas de acesso à justiça.

A primeira onda reúne os esforços de incrementação do acesso à justiça através da prestação de serviços jurídicos para os pobres. Neste primeiro impulso, a atitude positiva do Estado no sentido de garantir o acesso resultou na melhoria das estruturas de assistência judiciária, de forma a universalizar a cobertura daqueles que dela necessitavam. Nos diferentes países, o aperfeiçoamento dos sistemas de assistência judiciária materializou-se na adopção de modelos distintos que variaram sobretudo entre a opção pela prestação de serviços jurídicos através de servidores públicos ou de advogados privados. Nesta primeira fase, a resolução dos problemas do acesso pela via da assistência judiciária evidenciou algumas limitações. Por um lado, a necessidade de se garantir a qualidade da assistência através de um grande número de profissionais com alta qualificação onerou consideravelmente o orçamento do Estado. Por outro lado, os sistemas de assistência judiciária foram idealizados para o tratamento da micro-litigação individual, excluindo, à partida, a representação de interesses difusos e colectivos.

Para responder a esta última limitação, a segunda onda de reformas destinou-se a uma reformulação procedimental e institucional de modo a permitir a representação dos direitos difusos e colectivos. Neste movimento, a revisão de noções tradicionais do processo civil de modo a permitir a autoria individual ou dos diferentes grupos na proposição de acções colectivas foi acompanhada pela acção pública e privada, no sentido de fomentar a criação de estruturas especializadas no tratamento das questões de interesse público.

\footnotetext{
${ }^{8}$ Neste período, um vasto conjunto de estudos sociojurídicos vieram identificar as muitas faces das desvantagens dos pobres face ao direito e à justiça. Se é certo que os bloqueios económicos, sociais e culturais ao acesso à justiça são gerais, não é menos verdade que as classes populares sofrem uma dupla vitimização. Neste sentido, a justiça é proporcionalmente mais cara para os cidadãos economicamente mais débeis (em regra titulares de acções de menor valor) e a lentidão dos processos é ainda sentida como um custo adicional. O distanciamento cultural e geográfico dos tribunais é igualmente mais acentuado para os mais pobres, que para além disso apresentam um défice mais elevado no que respeita ao conhecimento dos direitos e das garantias jurídicas existentes (Santos, 1987).
} 
Nesta progressão de soluções jurídico-institucionais de ampliação do acesso, a terceira onda teve como enfoque o acesso à justiça como um todo, estendendo a sua atenção para além da advocacia pública ou privada, judicial ou extrajudicial, de modo a alcançar o conjunto geral de instituições e mecanismos para processar, prevenir disputas e distribuir direitos. Esta abordagem do acesso à justiça estabelece um conjunto de possibilidades: (1) reformas processuais no sentido de redução dos custos e simplificação dos procedimentos; (2) desjudicialização, desprofissionalização e informalização da solução de conflitos; (3) especialização das estruturas e procedimentos judiciais para o tratamento de causas de particular relevância social; 9 (4) mudanças nos métodos de prestação dos serviços jurídicos. ${ }^{10}$

A teorização decorrente da investigação do Projecto Florença corresponde a uma primeira fase no que toca ao estado da arte do acesso à justiça. Este momento inicial atestou um optimismo geral nos modelos de interesse público, defendendo um ideal de serviço público democratizante, redistributivo e activista. Nesta lógica, tal como a moradia, a assistência à saúde ou a educação, o direito seria fornecido como bem público através do acesso à justiça. Esta abordagem intelectual alimentou-se sobretudo da crença no Estado-Providência como ponto de chegada das sociedades ocidentais (Mattei, 2007).

A segunda fase de produção de estudos acerca do acesso dá-se num pano de fundo de avanço do liberalismo económico, crise do Estado-Providência e, consequentemente, cortes orçamentais aos grandes esquemas de protecção social. Neste contexto de restrições ao investimento público, não é possível sustentar a hipótese de um movimento articulado de reforma jurídica no sentido da universalização do acesso (ibidem, 2007). De facto, muitos países deixaram de se preocupar com o estado insatisfatório dos seus sistemas de acesso, em alguns casos avançando mesmo para uma acentuada fase de privatização dos serviços jurídicos. ${ }^{11}$ Com base em Moorhead e Pleasence (2003), denomino esta fase pós-universalista.

\footnotetext{
${ }^{9}$ De que são exemplos a criação de tribunais especializados para o tratamento de pequenas causas, direitos do consumidor, casos de violência contra a mulher, etc.

${ }^{10}$ Por exemplo o recurso a profissionais paralegais e a existência de planos privados de assistência jurídica.

${ }^{11}$ Neste sentido, afirma Flood (2009:12): "O apoio judiciário, como meio de acesso à justiça, está a ser severamente restringido pelo governo. A escala da oferta está a ser reduzida, o nível de recursos deverá diminuir e há um esforço para externalizar mais os serviços de assistência jurídica para o sector privado. A este respeito, após 60 anos de existência, a assistência judiciária está a ser radicalmente transformada. Mas estaremos a assistir a uma nova idade de ouro do acesso à justiça? A questão ainda não é clara. Muitas destas mudanças foram iniciadas antes da actual crise financeira, que intensificou a profundidade e a dimensão dos problemas sofridos por pessoas comuns".
} 


\section{Pós-universalismo: redução de custos e racionalização das políticas públicas de acesso à justiça}

As hipóteses analíticas do trabalho de Cappelletti e Garth apontam para uma época de ouro do acesso à justiça assente no progressivo alargamento da política pública nesta área. Nos países centrais, esta expansão teve como cenário a prosperidade do Estado-Providência e as profissões jurídicas como actores principais. Em outras palavras, para além do propósito de prestação social da justiça, o desenvolvimento dos esquemas de assistência jurídica vinculou-se à capacidade de negociação das profissões jurídicas em defesa da expansão do mercado de trabalho e da garantia dos seus privilégios profissionais (Regan et al., 1999). Em tempos recentes, testemunha-se um esgotamento da agenda "justiça para todos" acompanhado de uma perda de controlo das profissões jurídicas sobre os processos de reforma do acesso à justiça. ${ }^{12}$

Como salientam Moorhead e Pleasence (2003: 1-3), a estratégia global de acesso à justiça assenta numa retracção da universalidade e passa a investir no racionamento dos serviços jurídicos, circunscrevendo-os ao atendimento dos mais carenciados. Trata-se de um afunilamento crescente na definição das necessidades jurídicas elegíveis para a assistência jurídica que, estando de acordo com os propósitos de racionalização da gestão pública, colide com o projecto de um sistema jurídico igualitário. Não é à toa que os esforços analíticos desta segunda fase se dedicam sobretudo a discutir a discrepância entre o acesso à justiça enquanto princípio e o acesso à justiça enquanto prática. A reflexão teórica deste novo período pode ser organizada em dois tipos de abordagem: top down e bottom up (Sanderfur, 2008).

A abordagem bottom up debruça-se sobre o estudo dos problemas e necessidades jurídicas e dos meios de resolução de conflitos disponíveis. Ao deter-se na identificação dos problemas e conflitos sociais que se podem travestir em problemas e conflitos jurídicos, esta abordagem dá atenção às vivências e experiências pessoais na busca de soluções para as questões quotidianas, interessando-se sobretudo por atestar a acessibilidade das instâncias jurídicas no encaminhamento dos problemas sociais face à existência de um conjunto de outras instâncias de resolução de conflitos (Pleasence et al., 2004; Genn, 1999; Legal Services Corporation, 2004).

Este campo destaca-se sobretudo porque permite identificar o conjunto de conflitos e necessidades carentes de solução jurídica que não são correspondidos pelo sistema oficial, ${ }^{13}$ salientando não só as dificuldades do

${ }^{12}$ De acordo com Blankenburg (1999), dado o enfraquecimento e fragmentação das profissões jurídicas, estas já não reúnem condições para resistir às reformas jurídicas no sector da assistência jurídica. ${ }^{13}$ É vasta a bibliografia sobre as necessidades jurídicas não correspondidas pelo Estado (unmet legal needs); para um estudo de referência teórica e metodológica sobre o tema, cf. Genn (1999). 
cidadão comum no acesso às estruturas legais, mas também o fosso entre os problemas e necessidades jurídicas do dia-a-dia e a cobertura da assistência prestada pelo Estado. ${ }^{14} \mathrm{O}$ estudo de Pleasence et al. (2004), por exemplo, demonstra a importância de um direccionamento da política pública para o reforço da informação e consulta jurídicas e o aumento da consciência dos direitos e dos procedimentos por parte dos cidadãos. Ao mapear os motivos que levam a uma acção jurídica face a um problema social, demonstra que muitas pessoas não estão capacitadas para transitar pelo labirinto burocrático das estruturas do Estado. Em cada cinco problemas passíveis de serem conduzidos para uma solução jurídica, pelo menos um não recebe nenhum encaminhamento, isto porque ou as pessoas não sabem os procedimentos a adoptar ou estão demasiado amedrontadas para agir.

A investigação numa abordagem top down explora as discrepâncias no acesso à justiça ao analisar a forma como o direito e o sistema jurídico podem ou não facilitar aos cidadãos a realização dos seus interesses. Neste sentido, avalia-se como a pró-actividade ou distanciamento das instituições e as ferramentas disponíveis nas leis e nos procedimentos podem afectar a estratégia de recurso às estruturas jurídicas por parte dos indivíduos e dos grupos sociais. Entre outras variáveis, são analisadas: a complexidade das leis processuais, o papel de advogados e de outros profissionais do direito, a organização e cobertura dos serviços jurídicos, etc. (Paterson e Goriely, 1996, Regan et al., 1999, Zemans, 1996, Rhudy, 2000). Uma evidência empírica das discrepâncias na incorporação top down das demandas sociais por direitos é o facto de, neste momento, enquanto alguns interesses e problemas estão compreendidos pelo direito, sendo legalmente accionáveis, outros tantos desfrutam de uma institucionalização parcial ou precária, sendo ainda objecto de luta social e política para a sua efectivação ${ }^{15}$ (Sandefur, 2008).

Um terceiro eixo analítico, que reúne as perspectivas top down e bottom up, analisa as inovações desenvolvidas ao nível do Estado, da comunidade ou do mercado no sentido de suprir o défice na prestação dos serviços jurídicos: serviços assalariados, planos de assistência jurídica, educação para os direitos, capacitação jurídica dos cidadãos, ${ }^{16}$ etc. Com o abandono das tentativas de universalismo, a actual fragmentação das estruturas de acesso potencia inovações comunitárias ou institucionais orientadas tanto por uma

\footnotetext{
${ }_{14}$ Para um levantamento das necessidades jurídicas não atendidas pelos programas oficiais de assistência jurídica nos Estados Unidos, cf. Legal Services Corporation (2004).

${ }^{15}$ Uma análise dos constrangimentos dos tribunais na incorporação das demandas sociais pode ser vista em Rosenberg (2008).

${ }^{16}$ Um estudo detido das inovações institucionais e comunitárias de acesso à justiça desenvolvidas no Brasil vê-se em Santos (2007).
} 
perspectiva de radicalização dos serviços jurídicos, incentivo à autonomia dos cidadãos e intervenção activa junto das instituições jurídicas, como por uma perspectiva de criação de alternativas minimalistas que permitam uma gestão dos serviços com redução de custos (Moorhead e Pleasence, 2003, Santos, 2007, Baldwin, 2000).

Não sendo possível prever o destino das recentes reformas no âmbito do acesso à justiça, é certo que, cada vez mais, a construção de uma política pública democrática nesta área dependerá de uma acção coordenada entre as diferentes estruturas e serviços jurídicos (instituições judiciais, faculdades de direito, ordem dos advogados, programas de informação, aconselhamento e apoio judiciário, entre outras) e a acção individual e colectiva dos cidadãos (Rhode, 2004).

$\mathrm{Na}$ actualidade, a configuração política do acesso é uma arquitectura instável na qual interferem significativamente as diferentes aspirações e interesses dos seus protagonistas (poder político, profissionais do direito/acesso, cidadãos, movimentos e organizações sociais). Se nalgumas situações a acomodação dos interesses e aspirações pode resultar na mitigação da importância política do tema do acesso, noutras o confronto de posições pode fazer do acesso à justiça um tema de acentuada disputa e debate.

\section{As transformações de um acesso à justiça multiforme: o caso de São Paulo} A análise precedente permite inferir uma evolução do significado sociopolítico do acesso à justiça ao longo do Estado moderno. Idealizado inicialmente como um direito formal, vazio de efectividade, numa concepção de Estado liberal, nos moldes de um Estado-Providência o acesso à justiça passa a ser concebido como política social de promoção do direito por parte do Estado, traduzindo-se num movimento abrangente de reformas tendo em vista a sua universalização. Num período de crise do Estado-Providência, a aposta na promoção social através do direito é enfraquecida, resultando na restrição do acesso e no racionamento dos serviços jurídicos públicos. Se em alguns países centrais é possível falar de uma certa linearidade na assunção de responsabilidades sociais e na distribuição de direitos pelo Estado, nas sociedades periféricas e semiperiféricas a relação entre a garantia de direitos, as expectativas sociais e as respostas da justiça assume um significado inteiramente distinto.

Em países semiperiféricos, dos quais é exemplo o Brasil, o recente processo de consolidação democrática tem-se traduzido numa construção exultante de direitos (políticos, económicos, sociais e culturais) (Santos, 2007). Este curto-circuito histórico de direitos (Santos et al., 1996), acompanhado da introdução de medidas neoliberais de redução do investimento 
social do Estado, tem-se concretizado na introdução de reformas jurídicas vacilantes entre a consolidação de uma política social de acesso à justiça e a adopção de soluções de privatização/fragmentação dos serviços jurídicos e neutralização da importância política e social da justiça. Neste movimento chocam aspirações e interesses divergentes, a influência e o poder de mobilização dos actores sociais tanto podem invisibilizar o acesso enquanto tema da agenda de reformas do Estado, como podem convertê-lo em objecto de acirrada disputa política. Nesta secção, a apresentação do estudo de caso de São Paulo demonstra como o enfrentamento de aspirações e práticas distintas das instituições, das profissões jurídicas, dos movimentos e organizações transformam o acesso num tema quente da agenda social e política.

A evolução dos regimes políticos brasileiros consolidou a preferência por um modelo público de acesso com criação de um corpo profissional próprio dedicado à informação e consulta jurídicas, judicial e extrajudicial, e ao patrocínio judiciário. Com a constituição de 1988, esta entidade passou a ser denominada Defensoria Pública ${ }^{17}$ e, atendendo às características da organização judiciária brasileira, a sua criação foi prevista no âmbito estadual e federal (Alves, 2005).

A previsão de um modelo público de assistência judiciária assente na criação de defensorias públicas não assegura, só por si, a consolidação destas instituições e o fortalecimento do seu papel na defesa de direitos. De facto, a afirmação das defensorias públicas no Brasil é gradual e caracteriza-se por uma grande disparidade entre a previsão constitucional e a prática. Estudos de diagnóstico sobre o funcionamento das defensorias públicas no Brasil apontam, em alguns estados, para a timidez ou resistência dos governos estaduais em investir na criação ou no apetrechamento administrativo e financeiro desta instituição (Secretaria da Reforma do Judiciário, 2006). Até ao momento, nem todos os estados da federação brasileira têm defensorias públicas implantadas $;{ }^{18}$ por outro lado, em alguns estados a sua implantação recente aponta para um longo caminho a percorrer em busca de reconhecimento e consolidação, como ocorre no estado de São Paulo.

\footnotetext{
${ }_{17}$ São variados os exemplos de iniciativas institucionais e comunitárias no âmbito do acesso à justiça no Brasil. Este artigo limita a sua abordagem à actuação da defensoria, dada sua condição de instituição central do sistema de acesso à justiça.

${ }^{18}$ Os estados do Paraná e Goiás ainda não têm as suas defensorias estruturadas. O estado de Santa Catarina, por sua vez, instituiu um regime de Defensoria Dativa levado a cabo pela Ordem dos Advogados, modelo de assistência judiciária que está a ser questionado no tribunal constitucional (o tribunal constitucional no Brasil não se chama Tribunal Constitucional) (Secretaria da Reforma do Judiciário, 2009).
} 


\section{A reforma do sistema oficial de acesso à justiça}

Até à criação da Defensoria Pública, o sistema oficial de acesso à justiça do estado de São Paulo estava ligado ao poder executivo através da Procuradoria de Assistência Judiciária (PAJ). Ao longo dos anos, o trabalho da PAJ padecia de sérios problemas relacionados com a falta de autonomia do órgão e com o curto alcance dos serviços prestados (Maffezoli, 2005; Defensoria Pública do Estado de São Paulo, 2008). O número de procuradores de assistência judiciária não permitia atender à demanda existente em todo o estado. ${ }^{19}$ Este défice no atendimento era suprido com o estabelecimento de protocolos com outras entidades, de modo a remunerar advogados privados pela proposição de acções ou pela defesa em processos. Um dos maiores protocolos de assistência judiciária era mantido com a seccional de São Paulo da Ordem dos Advogados.

A Ordem dos Advogados constituiu-se, assim, como uma das protagonistas do acesso à justiça colmatando o défice de atendimento do sistema oficial. Nas comarcas que não dispunham do atendimento da PAJ, a assistência jurídica era garantida pelos advogados cadastrados pela Ordem, remunerados por tipo de acção com verbas do Fundo de Assistência Judiciária. ${ }^{20}$

Diversas entidades estiveram envolvidas no questionamento da situação do acesso à justiça em São Paulo, colocando na agenda a reivindicação pela criação de uma defensoria pública estadual. Um anteprojecto de lei orgânica para a criação da defensoria foi apresentado pela sociedade civil ao governo do estado e beneficiou de uma discussão alargada que envolveu diferentes organizações sociais, profissionais do direito e académicos. ${ }^{21}$

\footnotetext{
19 Até à criação da Defensoria Pública, o quadro do acesso à justiça em São Paulo era o seguinte: numa organização judiciária com 225 comarcas, 95 foros distritais e regionais, 1310 varas judiciais e juizados especiais, 1592 juízes e desembargadores e 1700 promotores, a PAJ contava com 346 procuradores do estado, que actuavam em 21 das mais de 300 comarcas e foros distritais e regionais do estado; na cidade de São Paulo não eram atendidos pela PAJ: nenhuma das varas criminais dos foros regionais; nenhuma das varas de infância e juventude da capital (excepto as varas especializadas em adolescentes em conflito com a lei); nenhum dos tribunais do júri dos foros regionais; e nenhuma das varas do Foro Regional de Pinheiros (http://www.movimentopeladefensoriapublica. hpg.com.br/mapa.htm).

${ }^{20}$ Fundo especial de despesa criado em 1984, pela lei 4476/84, composto por parcelas das custas judiciais e extrajudiciais com a finalidade de custear a prestação de assistência judiciária às pessoas carentes (http://www.movimentopeladefensoriapublica.hpg.com.br/mapa.htm).

${ }^{21} \mathrm{O}$ aprimoramento do anteprojecto de lei orgânica da defensoria, coordenado pelo Sindicato dos Procuradores do Estado, das Autarquias, das Fundações e das Universidades Públicas do Estado de São Paulo (SINDPROESP), contou com a participação de diversas entidades da sociedade civil organizada. A discussão em torno do anteprojecto impulsionou a criação do Movimento pela Defensoria Pública. Em Junho de 2002, o acto de lançamento do movimento reuniu mais de 400 organizações e movimentos sociais (http://www.movimentopeladefensoriapublica.hpg.com. br/historico.htm).
} 
Em 2006, a criação da Defensoria Pública do Estado de São Paulo inovou o cenário institucional brasileiro, prevendo mecanismos de participação social até então inexistentes nas restantes defensorias (realização de conferências públicas, presença de um ouvidor externo à instituição, entre outros). ${ }^{22}$

Não bastava criar um outro órgão e só mudar o nome, nós queríamos um novo paradigma. Com base numa visão crítica do sistema de justiça e das próprias instituições, tentamos incorporar uma série de experiências de acesso à justiça mais amplas, pensando não só naquela assistência judiciária, na representação postulatória em juízo, mas sobretudo na prevenção, na reivindicação de direitos, na utilização de meios alternativos de resolução de conflitos e de um corpo multidisciplinar de apoio para que a nossa intervenção não ficasse apenas atrelada ao aspecto jurídico e fosse uma intervenção mais efectiva, com a utilização, por exemplo, de acções colectivas, que nós víamos como um instrumento imprescindível. Do ponto de vista da organização da instituição, nossa preocupação era assegurar um grau de democratização diferenciado em relação às outras instituições jurídicas, sobretudo porque todas as entidades e movimentos sociais que tinham contacto com o Ministério Público e com o judiciário tinham severas críticas em relação à forma de auto-organização, controle, participação social e democratização interna desses órgãos. (Entrevista a Defensor Público, integrante do Movimento pela Defensoria Pública)

Por outro lado, a nova instituição herdou os problemas da assistência judiciária do estado de São Paulo, nomeadamente o défice estrutural deixado pela antiga PAJ e a necessidade de manutenção dos protocolos com outras entidades e, consequentemente, tensões com a Ordem dos Advogados na definição das prioridades da política pública de acesso. Desde a criação da defensoria, estes problemas repercutiram-se na criação de um fórum social de fortalecimento e valorização da entidade, em protestos públicos (com greve dos defensores) e na paralisação da prestação de serviços por parte da Ordem dos Advogados.

\section{A Defensoria Pública: nova instituição, velhos problemas}

A Defensoria Pública foi criada com um quadro funcional de 400 defensores ${ }^{23}$ o que representou uma dotação de 50 funcionários a mais face ao antigo quadro de procuradores de assistência judiciária. Consequentemente,

\footnotetext{
${ }_{22}$ Posteriormente, a Lei Complementar n. ${ }^{\circ}$ 132, de 07 de Outubro de 2009, veio incrementar a orgânica das defensorias públicas no Brasil, uniformizando o seu funcionamento e regulando a sua autonomia administrativa e financeira. A lei também introduziu critérios de transparência na gestão das defensorias instituindo, a exemplo da Defensoria Pública do Estado de São Paulo, a figura do ouvidor externo à instituição.

${ }^{23}$ Artigo 4. ${ }^{\circ}$ das Disposições Transitórias da Lei Complementar n. ${ }^{\circ}$ 988, de 09 de Janeiro de 2006.
} 
não houve diferenças substanciais no que toca à cobertura dos serviços entre a nova defensoria e a antiga PAJ.

Dada a impossibilidade de estender os serviços da defensoria a todo o estado, conservou-se em São Paulo o sistema misto de assistência judiciária, combinando um modelo público de assistência com um modelo privado. A Defensoria Pública passou a gerir o Fundo de Assistência Judiciária e, de acordo com sua lei orgânica, ficou condicionada a manter o protocolo com a Ordem dos Advogados em carácter complementar, de forma a garantir o atendimento jurídico à população de todo o estado. ${ }^{24}$

A conjugação desse modelo misto de assistência judiciária desenvolve-se num ambiente de tensões e disputa entre as profissões jurídicas com forte pressão política na defesa de cada um dos modelos. Em consonância com as questões analíticas que o actual quadro teórico do acesso à justiça invoca, as manifestações das diferentes associações profissionais têm circundado o dilema entre a importância da garantia da igualdade através da ampliação do acesso à justiça e a necessidade de eleição de prioridades na política pública face à inelasticidade dos recursos do Estado.

Assim, o modelo público é defendido pelo que representa em termos de economia de custos e eficácia dos serviços. A Associação Paulista de Defensores Públicos argumenta que, num ano, enquanto 400 defensores atendem cerca de 850 mil pessoas, os 47 mil advogados inscritos no protocolo com a Ordem atendem aproximadamente um milhão de pessoas. O investimento no modelo público é menos dispendioso para o Estado, uma vez que, de um total de 365 milhões de recursos gastos pela defensoria, 75\% (272 milhões) são destinados ao pagamento dos serviços da Ordem dos Advogados, 18 milhões de reais são gastos com outros protocolos e 75 milhões de reais são gastos com a defensoria em si. Estima-se que, aumentando o contingente de defensores para 1600 - de forma a atender toda a demanda de acesso à justiça existente no estado - haveria uma capacidade de 3,4 milhões de atendimentos por ano, o dobro do que é realizado pela Ordem (1,85 milhões), e o custo seria de 300 milhões de reais, uma economia de 65 milhões de reais em relação ao montante de recursos que é investido na manutenção do sistema actual.

Por outro lado, na defesa do modelo privado, a seccional de São Paulo da Ordem dos Advogados sustenta que, na prática, a assistência jurídica aos pobres do estado de São Paulo tem sido feita pelos 47 mil advogados inscritos na Ordem e não pelos 400 defensores públicos. Enquanto um

\footnotetext{
${ }^{24}$ De acordo com o artigo 234 da Lei Complementar n. ${ }^{\circ}$ 988, de 09 de Janeiro de 2006, a Defensoria Pública manterá o protocolo com a Seccional de São Paulo da Ordem dos Advogados do Brasil, visando implementar, de forma suplementar, as suas atribuições institucionais.
} 
defensor é remunerado em média com 8000 reais por mês, os advogados recebem, por exemplo, 600 reais para patrocinar um processo criminal do início ao fim - o que pode durar até 5 anos -, arcando com todos os encargos. Acresce que, enquanto a defensoria contabiliza todos os atendimentos que faz, a Ordem contabiliza apenas as acções ingressadas e os actos nos processos, as consultas feitas aos advogados não são remuneradas. A afirmação de que o modelo público representa uma economia de custos para o Estado é ainda rebatida com o argumento de que os recursos que remuneram os serviços prestados pela Ordem não são recursos públicos. Enquanto a ampliação e o apetrechamento da defensoria depende de investimento por parte do orçamento do Estado, o convénio com a Ordem tem garantido a cobertura da assistência jurídica gratuita através de um fundo alimentado pelas custas judiciais, isto é, resultante do patrocínio de outros advogados.

O conflito alimenta-se da oscilação da política pública entre a radicalização e a minimalização dos serviços jurídicos. Neste sentido, o debate entre as profissões jurídicas aponta para uma competição entre um modelo individualista de assistência judiciária e um modelo de interesse público.

$\mathrm{O}$ convênio com a $\mathrm{OAB}$ não disponibiliza atendimento integral à população, pois apenas a Defensoria Pública tem como obrigação institucional a realização de atividades de educação em direitos e mediação de conflitos e a proteção coletiva dos necessitados através de ações civis públicas, contando com profissionais com dedicação exclusiva à assistência gratuita, elemento essencial para que não se confundam interesses públicos e privados. (Nota oficial da Associação Paulista de Defensores Públicos em resposta à Secretaria da Justiça e da Defesa da Cidadania)

No caso dos atendimentos prestados por via do protocolo de assistência judiciária com a Ordem, os advogados recebem por acções propostas e pela defesa nos processos. Naturalmente, o patrocínio de acções colectivas ou a defesa de interesses difusos representa o mesmo ganho da actuação em acções individuais e uma exigência muito maior de trabalho e preparação.

A defensoria, por sua vez, apresenta uma orgânica peculiar, sobretudo no que toca à criação de mecanismos de participação social e ao tratamento de questões de interesse público. Neste sentido, o plano de actividades da defensoria é elaborado tendo por base as prioridades eleitas em conferências públicas bianuais. A instituição conta igualmente com um ouvidor externo, indicado pela sociedade civil, e espaços abertos para a participação de representantes de movimentos e organizações sociais e cidadãos nas reuniões do Conselho Geral. 
A organização da defensoria procura atender aos conflitos estruturais e às questões colectivas levantadas pelos movimentos e organizações sociais em São Paulo. Nesse sentido, tem apostado na criação de núcleos especializados: Núcleo de Habitação e Urbanismo, Núcleo da Situação Carcerária, Núcleo da Infância e da Juventude, Núcleo de Cidadania e Direitos Humanos, Núcleo dos Direitos do Idoso, Núcleo de Promoção e Defesa dos Direitos da Mulher e Núcleo de Combate ao Racismo e Preconceito..$^{25}$

Neste âmbito, o melhor exemplo da pró-actividade da defensoria junto das demandas colectivas e da acção dos movimentos e organizações sociais é a actuação do Núcleo Especializado de Habitação e Urbanismo.

O Núcleo tem se valido amplamente da legitimidade da Defensoria Pública para propor ações civis públicas, mas também tem procurado estimular as associações a participarem das ações como co-autoras. Trata-se não só de uma estratégia processual, mas também política, para que as comunidades pobres possam participar diretamente. Temos tido sucesso com relação à questão da legitimidade, mas é preciso muita paciência para mostrar a importância do nosso trabalho. (Carlos Loureiro, Coordenador do Núcleo Especializado de Habitação e Urbanismo, APADEP em notícia, Ano I, n. ${ }^{\circ}$ 04:3)

Estima-se que o núcleo já tenha proposto mais de 70 acções colectivas na defesa do direito de moradia.

As decisões obtidas pelas ações civis públicas da defensoria, parte delas feitas em parceria com o Centro Gaspar Garcia ou com a União dos Movimentos de Moradia ou outras organizações tem criado uma nova cultura jurídica do direito à moradia no estado de São Paulo, que é bastante recente; tenho até a impressão que esse processo é uma referência nacional, porque eu não sei se outros estados do Brasil têm feito um processo tão intenso de atuação no campo judicial, de judicialização do direito à moradia como tem sido feito no estado de São Paulo nesses últimos anos, principalmente a partir da parceria com a Defensoria Pública. A gente tem utilizado um termo importante que é o "advocacy", utilizar o judiciário cotidianamente na defesa de direitos, a gente não utilizava isso, a gente sempre tinha outras formas de

\footnotetext{
${ }^{25}$ A Defensoria Pública de São Paulo conta com a existência de núcleos especializados - de natureza permanente - cujo objectivo é promover uma actuação estratégica da instituição em áreas de importância sensível. Os núcleos também propõem acções judiciais e são responsáveis por coordenar o accionamento de Cortes Internacionais quando for necessário. Cada núcleo possui um Defensor Coordenador - com dedicação exclusiva ao cargo - e uma equipa de defensores integrantes. (http://www.defensoria.sp.gov.br/dpesp/Default.aspx?idPagina=3145).
} 
atuação, atuando ou pressionando o poder público ou através do poder legislativo, mas pouquíssimas vezes utilizando o judiciário e a gente fez isso de uma forma intensa nesses últimos dois anos, como a Defensoria Pública propiciou essa abertura. Temos feito isso muito, principalmente utilizando as ações coletivas para pressionar o poder público na garantia desses direitos. (Entrevista a Advogado, Central dos Movimentos Populares, União dos Movimentos de Moradia, Centro Gaspar Garcia de Direitos Humanos)

Resultam das entrevistas realizadas junto de representantes dos movimentos e organizações sociais apreciações e expectativas positivas quanto à contribuição da defensoria para a melhoria do acesso à justiça. Quando comparados os serviços da defensoria com a assistência jurídica prestada pela Ordem dos Advogados, os defensores foram diferenciados pela dedicação, compromisso social, qualidade técnica e de formação. A defensoria é vista como um projecto colectivo e, consequentemente, um importante suporte para as lutas sociais.

A defensoria do estado de São Paulo surge de uma forma muito diferente de outras defensorias, surge dessa demanda dos movimentos sociais e o governo, ao não oferecer para a defensoria as condições de funcionamento adequadas, fragiliza muito a demanda represada que esses movimentos sociais têm (...). A defensoria, do ponto de vista do sistema de justiça, é uma esperança hoje para que muitas das demandas possam ser atendidas, e como a defensoria foi construída pelos movimentos sociais, os movimentos sociais, independente de que grau de participação e de importância que tenham os militantes, compreendem muito bem a importância desse mecanismo (...). Você pode procurar os movimentos sociais do estado de São Paulo, todos eles se sentem responsáveis pela defensoria. (Entrevista a Representante do Fórum Estadual de Defesa da Criança e do Adolescente)

De acordo com um contexto pós-universalista, a prestação de serviços pela defensoria é altamente limitada, circunscrevendo-se ao atendimento de cidadãos com rendimento inferior a 3 salários mínimos. Mesmo com restrição nos critérios de elegibilidade para assistência jurídica, o número de potenciais utentes dos serviços da defensoria é expressivo. O cruzamento do número de defensores com o tamanho da população de baixa renda elegível para atendimento resulta numa razão de 72 mil pessoas por defensor. A relação defensor público por potencial usuário de São Paulo é a terceira pior do país, sendo a média nacional 32 mil pessoas por defensor (Secretaria da Reforma do Judiciário, 2009). Naturalmente, esta realidade traduz-se numa sobrecarga de acções e de atendimentos individuais cíveis 
e criminais. ${ }^{26}$ Acresce à sobrecarga de trabalho a existência de sérias restrições orçamentais. Para o ano corrente, o orçamento do Tribunal de Justiça aumentou em $\mathrm{R} \$ 174$ milhões e o do Ministério Público em quase $\mathrm{R} \$ 80$ milhões, enquanto a Defensoria Pública recebeu pouco mais de $\mathrm{R} \$ 2$ milhões de aumento em relação ao ano anterior (Belloque, 2010).

Os obstáculos estruturais e funcionais concretizam-se em dificuldades de ampliação dos critérios de elegibilidade, de garantia de qualidade dos serviços, de consolidação do trabalho de litigação colectiva (que exige mais tempo e preparo e, portanto, um maior investimento em pessoal e em formação) e de investimento na orientação e capacitação jurídica dos cidadãos.

O Estado e o Ministério Público não funcionam direito, o judiciário só vai receber a pessoa depois que passou nos outros órgãos. A Defensoria Pública tem um papel reduzido porque são muito poucos defensores públicos para o tamanho do estado de São Paulo. (...) a própria Defensoria Pública devia estar orientando juridicamente as pessoas. Ela não faz isso porque ela não dá conta. Mas ela poderia estar orientando juridicamente essa idéia de cidadania. Eu penso que você traz a idéia de que o direito, o mundo jurídico, esse conhecimento pode te fortalecer, você pode transformar essa multidão de gente que não tem acesso à justiça numa cidadania autônoma. Você pode transformar. Eu acho que a defensoria tem esse papel. (Entrevista a Representante da União de Mulheres de São Paulo)

As deficiências estruturais e de orçamento têm sido enfrentadas pelos defensores públicos de forma política. Neste sentido, o Movimento Pela Defensoria foi revigorado em torno de um fórum de fortalecimento e valorização, que tem dinamizado protestos e intervenções públicas com o objectivo de pressionar o poder político a investir no aperfeiçoamento da instituição, em especial no aumento do número de defensores. ${ }^{27}$

A mobilização social e política em torno da valorização da defensoria não está isenta de críticas. Para os representantes políticos, a defensoria é apoiada e valorizada pelo governo, o défice de pessoal e a necessidade de consolidação do seu funcionamento justifica-se, uma vez que se trata de uma instituição criada recentemente. Defendem ainda que não se pode falar na precariedade do acesso à justiça pela população do estado de São Paulo já que a assistência judiciária também é suportada pelo protocolo com a Ordem dos Advogados. Na visão de alguns defensores e líderes dos

${ }^{26}$ A defensoria estima que participa em mais de 180 mil audiências, na área cível e criminal. $\mathrm{Na}$ área cível são propostas cerca de 50 mil acções por ano. $\mathrm{Na}$ área criminal, são impetrados cerca de 15 mil habeas corpus em favor de réus presos (Associação Paulista dos Defensores Públicos, 2008: 7).

${ }^{27}$ Em 2009, o quadro funcional da defensoria foi aumentado para 500 defensores. 
movimentos sociais, o governo estadual não tem investido na defensoria e insiste num modelo de acesso à justiça através da assistência por parte de advogados particulares, pois vê na actuação da defensoria a criação de um projecto político junto dos movimentos e organizações sociais que causa desconforto e desconfiança.

\section{Conclusão: do movimento de acesso à justiça ao acesso à justiça em movimento}

Do ponto de vista do impacto social é possível explorar o tema do acesso à justiça através de dois ângulos de abordagem: a igualdade de oportunidades (o sistema deve ser igualmente acessível a todos) e a igualdade de resultados (o sistema deve oferecer respostas que sejam individual e socialmente justas). Numa perspectiva em que o acesso à justiça está integrado na política social do Estado e num movimento universalista de reformas, a igualdade de oportunidades de acesso é vista como igualdade de resultados, isto é, a promoção do direito e da justiça é em si mesmo um meio de promoção da justiça social. $\mathrm{Na}$ actualidade, as mudanças no significado sociopolítico do acesso à justiça quebraram esta estreita ligação entre oportunidades e resultados.

A impossibilidade de uma política universalista de acesso à justiça e o fosso existente entre o acesso enquanto princípio e o acesso enquanto prática limitaram a discussão à necessidade de ampliação e garantia de oportunidades. A obtenção da igualdade de resultados através do direito constituiu-se, assim, num privilégio exclusivo dos indivíduos e grupos incluídos pelas instituições e estruturas jurídicas. Neste contexto, a luta social pela promoção da igualdade de resultados através do direito tem como primeira condição a luta social por oportunidades de acesso. Neste aspecto, o caso de São Paulo é exemplificativo, uma vez que a opção política de criação da Defensoria Pública assumiu os contornos de um movimento social em que, ao confronto de posições entre a Ordem do Advogados, o poder político e a Defensoria Pública, subjaz uma intensa mobilização social pela valorização e apetrechamento desta instituição.

O que foi definido no passado como um movimento abrangente de ondas de acesso à justiça é agora ressignificado como um acesso à justiça em movimento. Em outras palavras, a alteração da política pública do acesso passa a depender menos da introdução unidireccional de reformas jurídicas de cima para baixo, vinculando-se à combinação das aspirações e posicionamentos de diferentes actores: agentes políticos, profissões jurídicas, empresas, organizações e movimentos sociais.

A configuração política do acesso é, portanto, movediça. Dadas as divergências de interesses que estão em jogo, a introdução de reformas no âmbito 
do acesso à justiça oscila de acordo com a influência, o poder de negociação e a mobilização dos agentes em disputa. Nesse sentido, a construção de uma política democrática de acesso não é linear, está repleta de avanços e recuos e depende da integração das escolhas políticas e profissionais com uma lógica crescente de aproximação e apropriação do direito e da justiça pelos cidadãos.

\section{Referências bibliográficas}

Alves, Cleber Francisco (2005), A estruturação dos serviços de assistência jurídica no Brasil, na França e nos Estados Unidos e sua contribuição para garantir a igualdade de todos no acesso à justiça. Rio de Janeiro: Pontifícia Universidade Católica. Tese de Doutoramento.

Associação Paulista dos Defensores Públicos (2008), Fortalecimento da Defensoria Pública: Garantia de acesso à justiça à população carente. São Paulo.

Baldwin, John (2000), "Access to Justice: The English Experience with Small Claims". PREM Notes, 40. World Bank.

Belloque, Juliana (2010), "Defensoria Pública em São Paulo: Avanços e desafios”, Jornal Folha de São Paulo, 21 de Janeiro de 2010.

Blankenburg, Ehard (1999), "The Lawyers' Lobby and the Welfare State: The Political Economy of Legal Aid", in Francis Regan et al. (eds.) (1999), The Transformation of Legal Aid: Comparative and Historical Studies. Oxford: Oxford University Press.

Cappelletti, Mauro; Garth, Bryant (1988), O acesso à justiça. Porto Alegre: Sergio Antonio Fabris.

Comaille, Jacques (2009), "Sociologie politique de l'accès au droit et à la justice". Intervenção no Colóquio Internacional "O acesso ao direito e à justiça da família em transformação”. Coimbra, 27 de Novembro.

Defensoria Pública do Estado de São Paulo (2008), Relatório de Actividades 2006-2008. São Paulo.

Flood, John (2009), "The Transformation of Access to Law and Justice in England and Wales". Intervenção no Colóquio Internacional "O acesso ao direito e à justiça da família em transformação". Coimbra, 27 de Novembro.

Galanter, Marc (1974), "Why the 'Haves' Come out Ahead: Speculations on the limits of legal change", Law and Society Review, 9: 95-160.

Garapon, Antoine (1997), Bien juger - Essai sur le ritual judiciaire. Paris: Odyle Jacob.

Genn, Hazel (1999), Paths to Justice: What people do and think about going to law. Oxford: Hart Publishing.

Legal Services Corporation (2004), Documenting the Justice Gap in America: The current unmet civil legal needs of low-income americans. Washington: Legal Services Corporation. 
Maffezoli, Antonio José (2005), “Defensoria Pública em São Paulo”, in O Estado de São Paulo, espaço aberto. Publicado em 27 de Abril.

Mattei, Ugo (2007), “Access to Justice. A Renewed Global Issue?”, Electronic Journal of Comparative Law, 11.

Mccan, Michael (1994), Rights at Work. Chicago: The University of Chicago Press.

Moorhead, Richard; Pleasence, Pascoe (2003), After Universalism: Re-engineering Access to Justice. Oxford: Blackwell Publishing.

Paterson, Alan; Goriely, Tamara (eds.) (1996), A Reader on Resourcing Civil Justice. Oxford: Oxford University Press.

Pleasence, Pascoe et al. (2004), Causes of Action: Civil law and social justice. London: Legal Services Comission.

Regan, Francis et al. (eds.) (1999), The Transformation of Legal Aid: Comparative and Historical Studies. Oxford: OUP.

Rhode, Deborah (2004), Access to Justice. Oxford: Oxford University Press.

Rhudy, Robert J. (2000), “Expanding Access to Justice: Legal Aid Models for Latin America”, in Christina Biebesheimer; Francisco Mejía (eds.), Justice Beyond Our Borders: Judicial Reforms for Latin America and the Caribbean. Washington, D.C.: Interamerican Development Bank.

Rosenberg, Gerald (2008), The Hollow Hope: Can Courts Bring About Social Change? Chicago: The University Chicago Press.

Sanderfur, Rebecca (2008), "Access to Civil Justice and Race, Class and Gender Inequality”, Annual Review of Sociology, 34: 339-358.

Santos, Boaventura de Sousa (1987), "Introdução à Sociologia da Administração da Justiça”, Revista Crítica de Ciências Sociais, 21, 11-37.

Santos, Boaventura de Sousa (2002), Toward a New Legal Common Sense. London: Butterworths.

Santos, Boaventura de Sousa (2003), "Poderá o direito ser emancipatório?”, Revista Crítica de Ciências Sociais, 65: 3-76.

Santos, Boaventura de Sousa (2007), Para uma revolução democrática da justiça. São Paulo: Cortez.

Santos, Boaventura de Sousa et al. (1996), Os tribunais nas sociedades contemporâneas: o caso português. Porto: Afrontamento.

Secretaria da Reforma do Judiciário (2006), II Diagnóstico da Defensoria Pública no Brasil. Brasília: Secretaria da Reforma do Judiciário.

Secretaria da Reforma do Judiciário (2009), III Diagnóstico da Defensoria Pública no Brasil. Brasília: Secretaria da Reforma do Judiciário.

Sinhoretto, Jacqueline (2006), Ir aonde o povo está. São Paulo: Universidade de São Paulo. Tese de Doutoramento

Zemans, Fredrick H., (1996), "Recent Trends in the Organization of Legal Services", in Alan Paterson; Tamara Goriely (eds.), A Reader on Resourcing Civil Justice. Oxford: Oxford University Press. 